УДК 581.19

\title{
ОСОБЕННОСТИ СОДЕРЖАНИЯ ТАНИНОВ В ЛИСТЬЯХ ДРЕВЕСНЫХ РАСТЕНИЙ В ТЕХНОГЕННОЙ СРЕДЕ
}

\author{
(C) И.Л. Бухарина ${ }^{* 1}$, А.М. Кузьмина ${ }^{2}$ П.А. Кузьмин ${ }^{3}$ \\ ${ }^{1}$ Удмуртский государственный университет, Университетская ул., 1, \\ Ижевск, 426034 (Россия), e-mail: buharin@udmlink.ru \\ ${ }^{2}$ Ижевская государственная сельскохозяйственная академия, ул. Кирова, 16, \\ Ижевск, 426033 (Россия) \\ ${ }^{3}$ Казанский фредеральный университет, Казанская, 89, Елабуга, 423600 \\ (Россия)
}

Изучена динамика содержания танинов в листьях древесных видов растений, произрастающих в насаждениях различных экологических категорий. Исследования проведены на примере города Набережные Челны Республики Татарстан. Комплексный индекс загрязнения атмосферы города показывает очень высокое загрязнение и превышение уровня предельно допустимой концентрации по бенз(а)пирену, формальдегиду, фенолам и оксидам углерода и азота. Показано участие данного метаболита в адаптивных реакциях древесных растений к условиям техногенной среды. Выявлено, что содержание танинов в листьях растений увеличивается в течение всего периода активной вегетации и достигает максимального значения в августе. На содержание танинов в листьях влияет степень техногенной нагрузки и особенности метеорологических условий вегетационного периода. Динамика накопления танинов в листьях древесных растений имеет видовую специфику. Для создания примагистральных посадок предпочтение следует отдавать таким видам древесных растений, как клен остролистный, клен американский, береза повислая, а применение липы мелколистной и тополя бальзамического - ограничить. Для создания насаждений санитарно-защитных зон промышленных предприятий наиболее обоснованными древесными породами являются липа мелколистная, тополь бальзамический, клен остролистный и береза повислая.

Ключевые слова: танины, древесные насаждения, техногенная среда, адаптивные реакции.

\section{Введение}

Важной проблемой современности является усиление средопреобразующих функций городских насаждений и создание экологически благоприятной среды. Установлено, что с увеличением степени экстремальности условий произрастания в клетках устойчивых видов растений синтезируется ряд веществ, выполняющих защитные функции, в том числе антиоксидантные. В адаптивных реакциях задействованы различные метаболиты, в том числе фенольные соединения, представителями которых являются танины. Фенольные соединения влияют на процессы роста и развития. Механизм их действия на рост растений не ясен [1-4].

В последнее время высказывается мнение о возможности использования вторичных метаболитов для характеристики физиологического состояния растений. У растений, устойчивых к загрязнению среды, благодаря синтезу углеродсодержащих соединений (пигменты, лигнин, воска, фенолы, дубильные вещест-

Бухарина Ирина Леонидовна - профессор кафедры инженерной защиты окружающей среды, доктор биологических наук, e-mail: buharin@udmlink.ru Кузьмин Петр Анатольевич - доцент кафедры биологии и экологии, кандидат сельскохозяйственных наук, e-mail: petrkuzmin84@yandex.ru

Кузьмина Айгуль Мухаметнагимовна - аспирант, e-mail: amsharifullina@yandex.ru

\footnotetext{
* Автор, с которым следует вести переписку.
}

ва и др.) формируется высокая конструкционная цена листьев (энергетические затраты на образование единицы массы листьев). Эти вещества, повидимому, могут снижать действие экологического стресса и предохранять листья от потери влаги при высыхании и замерзании, действии ультрафиолетового излучения [5]. Это свидетельствует 
о том, что ФС в растительной клетке могут играть значимую роль в адаптации растений к различным стрессовым факторам [6-8].

Тем не менее в настоящее время нет четкого понимания метаболизма этих соединений при воздействии на растения негативных факторов, и этот вопрос требует дальнейшего изучения.

Исходя из этого мы поставили перед собой цель изучить особенности динамики содержания в листьях танинов, как элемента антиоксидантной системы защиты, в период активной вегетации древесных растений, произрастающих в условиях городской среды в насаждениях разных экологических категорий в крупном промышленном центре г. Набережные Челны.

Набережные Челны входит в состав Республики Татарстан, которая расположена на территории Среднего Поволжья. Характеристика степени загрязнения атмосферного воздуха в местах произрастания древесных растений проведена нами на основе «Доклада об экологическом состоянии Республики Татарстан». Комплексный индекс загрязнения атмосферы (ИЗА) показывает очень высокое загрязнение (ИЗА $=15,3$, при ПДК $=5$ ) и превышение уровня предельно допустимой концентрации по бенз(а)пирену, формальдегиду, фенолам и оксидам углерода и азота. В С33 промышленных предприятий среднегодовое превышение отмечено по следующим веществам: по оксиду углерода в 2 раза; оксиду азота в 3 раза; диоксиду серы в 1,2 раза; формальдегиду в 5 раз; по фенолу в 1,7 раза; по бенз(а)пирену в 1,9 раза. В зоне магистральных посадок среднегодовое превышение отмечено по следующим веществам: по оксиду углерода в 3,4 раза, формальдегиду в 3,8 раза; по фенолу в 1,4 раза; по бенз(а)пирену в 1,5 раза [9].

\section{Экспериментальная часть}

Объектами исследования были древесные растения, широко представленные в озеленении города: аборигенные виды - клен остролистный (Acer platanoides L.), липа мелколистная (Tilia cordata Mill.) и береза повислая (Betula pendula Roth.); интродуцированные виды - клен ясенелистный (Acer negundo L.) и тополь бальзамический (Populus balsamifera L.). Изучаемые виды произрастали в примагистральных посадках (крупные магистрали Авто 1 и проспект Мира) и насаждениях санитарно-защитных зон (С33) промышленных предприятий $\mathrm{OAO}$ «КамАЗ» завод литейный и кузнечный, являющихся основными загрязнителями города. В качестве зон условного контроля (ЗУК) выбраны территории Челнинского лесничества (лесостепная зона, общая площадь 9539 га) для аборигенных видов (береза повислая, липа мелколистная и клен остролистный), а для интродуцированных видов (клен ясенелистный и тополь бальзамический) территория городского парка «Гренада» [10].

В насаждениях регулярным способом закладывали пробные площади (по 5 шт. в каждом районе, размером не менее 0,25 га). В пределах пробной площади проводили отбор (по 10 растений каждого вида) и нумерацию учетных древесных растений. Учетные особи имели хорошее жизненное состояние и средневозрастное онтогенетическое состояние $\left(\mathrm{g}_{2}\right)$. Для проведения агрохимических анализов на пробных площадях провели отбор почвенных проб (смешанная проба, составленная из индивидуально взятых проб по способу конверта) [11, 12].

Для проведения лабораторных физиолого-биохимических анализов отбирали пробы верхушечных вегетативных годичных побегов и их срединных (ассимилирующих) листьев. Отбор проводили со средней и нижней части (исключая нижние ветви) кроны древесных растений с южной экспозиции кроны. Смешанную пробу не проводили (каждая особь выступала как повторность), для каждой особи анализы проводили в трех повторениях. Содержание конденсированных танинов в листьях древесных растений определяли трижды в течение вегетации (июнь, июль, август) и в течение трех вегетационных периодов (2011-2013 гг.), используя перманганатометрический метод (метод Левенталя в модификации Курсанова) [13].

При проведении дисперсионного статистического анализа результаты лабораторных анализов усреднялись по насаждениям разных экологическим категорий. Математическую обработку результатов провели с применением статистического пакета Statistica 5.5. Для интерпретации полученных материалов использовали методы описательной статистики и дисперсионный многофакторный анализ (при последующей оценке различий методом множественного сравнения LSD-test). 


\section{Обсуждение результатов}

В 2011 г. метеорологические условия вегетационного периода древесных растений характеризовались повышенной температурой воздуха, превышением среднемноголетних данных в пределах $+3 \ldots+7{ }^{\circ} \mathrm{C}$, а также выпавшими осадками на уровне нормы. В 2012 и 2013 гг. были более засушливые условия, чем в 2011 г., превышение температуры над среднемноголетними данными составляло $+7 \ldots+11{ }^{\circ} \mathrm{C}$, а выпадение осадков было ниже нормы.

Проведенный агрохимический анализ показал, что почвы в насаждениях зон условного контроля имели слабощелочную реакцию $\left(\mathrm{pH}_{\mathrm{KCl}}=7,1-7,2\right)$, среднее содержание органического вещества $(5,3-5,8 \%)$, от повышенного до очень высокого содержание подвижного фосфора (115,4-291,3 мг/кг) и от высокого до очень высокого - обменного калия (210-314 мг/кг). В почвах было отмечено высокое содержание нитратных форм азота (210-405) и низкое содержание аммонийных форм азота (8,3-19,3 мг/кг). В насаждениях санитарно-защитных зон промышленных предприятий почвы характеризовались слабокислой и слабощелочной реакцией $\left(\mathrm{pH}_{\mathrm{KCl}}=6,7-7,5\right)$, содержанием органического вещества от среднего до повышенного (5,5-6,2\%), содержанием нитратных форм азота на уровне 247-300 мг/кг и аммонийных форм азота на уровне 6,1-14,9 мг/кг. В магистральных насаждениях почвы имели: обменную кислотность 7,4-7,7 $\left(\mathrm{pH}_{\mathrm{H} 2 \mathrm{O}}=8,4-8,6\right)$, характеризующую слабощелочную реакцию почв; низкое содержание органического вещества $(1,7-3,1 \%)$; от низкого до среднего содержание аммонийного азота $(6,4-8,1$ мг/кг) и подвижного фосфора $\left(\mathrm{P}_{2} \mathrm{O}_{5}=29,8-53,5\right.$ мг/кг); среднее содержание нитратного азота (164-175); от высокого до очень высокого содержание обменного калия $\left(\mathrm{K}_{2} \mathrm{O}=210-325\right.$ мг/кг).

Дисперсионный многофакторный анализ результатов исследований в 2011 г. выявил достоверность влияния видовых особенностей (уровень значимости $\mathrm{P}<10^{-5}$ ), комплекса условий места произрастания $\left(\mathrm{P}=8,37 \cdot 10^{-5}\right)$, сроков вегетации $\left(\mathrm{P}=1,16 \cdot 10^{-3}\right)$, а также воздействия этих факторов $\left(\mathrm{P}<10^{-5}\right)$ на содержание танинов в листьях древесных растений (табл.).

Результаты исследований в 2011 г. показали, что у всех изученных видов растений и во всех типах насаждений содержание танинов в листьях возрастает в ходе вегетации, достигая наибольших значений в августе. Наибольшими значениями показателя танинов характеризовались береза повислая, клен остролистный (11,87-11,89 и 11,27-11,63 мг/г сух. вещества соответственно), т.е. аборигенные виды.

У представителей рода клен наблюдались схожие особенности изменения в содержании танинов в листьях растений городских насаждений: в июне, в июле и в августе содержание танинов в листьях растений в насаждениях промышленных зон и в магистральных посадках было существенно ниже, чем в насаждениях зон условного контроля. При этом наибольшее снижение по сравнению с ЗУК наблюдалось у клена ясенелистного в июле (на 0,76 мг/г сух. в-ва) и в августе (на 0,67 мг/г сух. в-ва, при $\mathrm{HCP}_{05}=0,03$ ) в насаждениях промышленных зон в примагистральных посадках в августе (на 0,7 мг/г сух. в-ва, при $\left.\mathrm{HCP}_{05}=0,03\right)$. Это можно объяснить либо снижением синтеза данного метаболита, либо его интенсивным расходованием в защитных реакциях растений, так как именно эти месяцы по многолетним данным отличаются наибольшим уровнем загрязнения атмосферного воздуха в городе.

Различия в содержании танинов в листьях липы мелколистной и березы повислой в городских насаждениях в июне были схожи. В магистральных посадках и в насаждениях санзон растения отличались более низким содержанием танинов по сравнению с ЗУК. В июле результаты оказались отличными от июня. В листьях растений в магистральных посадках содержание танинов было значительно выше по сравнению с ЗУК. Видовые отличия у этих двух видов растений наблюдались лишь в августе. В листьях липы мелколистной содержание танинов было достоверно ниже, чем в насаждениях парковой и пригородной зоны, причем и в примагистральных посадках (на 0,12 мг/г сух. вещества), и в насаждениях санитарно-защитных зон промышленных предприятий (на 0,31 мг/г сух. в-ва, при $\mathrm{HCP}_{05}=0,03$ ). Особи березы повислой в этот период наблюдений в разных типах насаждений не имели достоверных различий с контролем по содержанию танинов.

Видоспецифичность реакции растения на условия произрастания наблюдалась у тополя бальзамического: в насаждениях промзон в июне и в июле содержание танинов в листьях растений превышало показатели ЗУК, а затем в августе, наоборот, значительно снижалось по сравнению с ЗУК. В магистральных посадках динамика показателя была иной: в июле - ниже, в июле - содержание танинов выше, чем в ЗУК, а в августе различий межу типами насаждений установлено не было. 
Динамика содержания танинов в листьях древесных растений, произрастающих насаждениях Набережные Челны, мг/г сух. в-ва

\begin{tabular}{|c|c|c|c|c|c|c|}
\hline \multirow[b]{2}{*}{$\begin{array}{c}\text { Категория } \\
\text { насаждений }\end{array}$} & \multirow[b]{2}{*}{ Месяц } & \multicolumn{5}{|c|}{ Вид растения } \\
\hline & & Tilia cordata Mill. & $\begin{array}{c}\text { Populus } \\
\text { balsamifera } \mathrm{L} .\end{array}$ & $\begin{array}{c}\text { Betula } \\
\text { pendula } \text { Roth. }\end{array}$ & $\begin{array}{c}\text { Acer } \\
\text { platanoides } \mathrm{L} .\end{array}$ & Acer negundo L. \\
\hline \multicolumn{7}{|c|}{2011 г. } \\
\hline \multirow{3}{*}{$\begin{array}{c}\text { ЗУК } \\
\left(\mathrm{HCP}_{05}=0,03\right)\end{array}$} & Июнь & 4,25 & 5,62 & 5,85 & 6,44 & 5,83 \\
\hline & Июль & 6,40 & 7,94 & 8,25 & 8,82 & 8,55 \\
\hline & Август & 8,01 & 11,00 & 11,89 & 11,63 & 9,46 \\
\hline \multirow{3}{*}{ C33 } & Июнь & 3,88 & 5,72 & 5,25 & 6,12 & 5,70 \\
\hline & Июль & 7,43 & 8,66 & 8,92 & 8,18 & 7,79 \\
\hline & Август & 7,70 & 10,99 & 11,87 & 11,27 & 8,79 \\
\hline \multirow{3}{*}{ МП } & Июнь & 4,16 & 5,34 & 5,26 & 6,18 & 5,55 \\
\hline & Июль & 6,79 & 9,73 & 8,57 & 8,13 & 8,49 \\
\hline & Август & 7,89 & 11,00 & 11,88 & 11,60 & 8,76 \\
\hline \multicolumn{7}{|c|}{2012 г. } \\
\hline \multirow{4}{*}{$\begin{array}{c}\text { ЗУК } \\
\left(\mathrm{HCP}_{05}=0,03\right)\end{array}$} & Июнь & 3,15 & 3,87 & 4,21 & 4,87 & 4,19 \\
\hline & Июль & 4,89 & 5,15 & 7,63 & 6,90 & 5,62 \\
\hline & Август & 8,15 & 6,95 & 10,22 & 8,45 & 7,61 \\
\hline & Июнь & 2,38 & 3,83 & 3,93 & 4,98 & 4,14 \\
\hline \multirow[t]{2}{*}{ C33 } & Июль & 5,35 & 5,79 & 8,26 & 6,12 & 4,84 \\
\hline & Август & 7,30 & 7,10 & 9,78 & 7,51 & 7,14 \\
\hline \multirow{3}{*}{ МП } & Июнь & 2,06 & 3,93 & 3,81 & 4,52 & 4,06 \\
\hline & Июль & 5,16 & 6,02 & 6,83 & 5,84 & 5,30 \\
\hline & Август & 6,89 & 7,36 & 8,34 & 7,57 & 6,97 \\
\hline \multicolumn{7}{|c|}{2013 г. } \\
\hline \multirow{3}{*}{$\begin{array}{c}\text { ЗУК } \\
\left(\mathrm{HCP}_{05}=0,03\right)\end{array}$} & Июнь & 2,79 & 3,55 & 4,03 & 4,50 & 3,95 \\
\hline & Июль & 4,44 & 4,80 & 7,17 & 6,57 & 5,24 \\
\hline & Август & 7,87 & 6,58 & 9,81 & 8,13 & 7,19 \\
\hline \multirow{3}{*}{ C33 } & Июнь & 2,18 & 3,50 & 3,34 & 4,66 & 3,84 \\
\hline & Июль & 5,10 & 5,38 & 7,83 & 5,79 & 4,55 \\
\hline & Август & 7,02 & 6,86 & 9,42 & 7,20 & 6,82 \\
\hline \multirow{3}{*}{ МП } & Июнь & 1,86 & 3,63 & 3,38 & 4,20 & 3,68 \\
\hline & Июль & 4,87 & 5,66 & 6,44 & 5,43 & 5,02 \\
\hline & Август & 6,59 & 7,06 & 8,00 & 7,25 & 6,58 \\
\hline
\end{tabular}

Примечание: ЗУК - зоны условного контроля; С33 - санитарно-защитные зоны промышленных предприятий; МП магистральные посадки

В последующие годы у липы мелколистной характер изменения в содержании танинов в разные месяцы наблюдений и в разных категориях насаждений был аналогичным, несмотря на более экстремальные метеорологические условия. Но следует отметить, что численные значения содержания танинов в листьях в 2012-2013 гг. были ниже по сравнению с 2011 г., причем это было характерно для всех изучаемых видов растений.

У березы повислой в 2012-2013 гг. в насаждениях С33 промышленных предприятий характер изменений в содержании танинов был аналогичен вегетационному периоду 2011 г. В магистральных посадках в условиях интенсивного техногенного воздействия в более сложные по метеоусловиям годы в течение всего периода наблюдений отмечалось значительное снижение содержания танинов в листьях по сравнению с контрольными насаждениями.

Аналогичные результаты отмечены и у изучаемых видов рода клен. В течение всего вегетационного периода растения в магистральных посадках и в насаждениях промзон имели более низкое содержание танинов в листьях по сравнению с ЗУК. Учитывая хорошее жизненное состояние представителей рода клен в исследуемых насаждениях, можно полагать, что снижение содержания этого метаболита связано с его защитными функциями и его расходованием на обеспечение защитных механизмом листа.

Что касается тополя бальзамического, то нам не удалось выявить устойчивых особенностей динамики данного метаболита в листьях в годы исследований, хотя результаты исследований 2012-2013 гг. были схожими. В насаждениях санитарно-защитных зон промышленных предприятий и в примагистральных посадках содержание танинов в листьях тополя бальзамического было достоверно выше, чем в ЗУК, за 
исключением июня, когда оно было достоверно ниже по сравнению с контрольными растениями, но не более чем на 0,05-0,04 мг/г сух. вещества, при $\left.\mathrm{HCP}_{05}=0,03\right)$.

Таким образом, можно заключить, что реакции различных видов растений на условия произрастания зависела не только от степени техногенной нагрузки, но и от складывающихся метеорологических условий в период вегетации растений.

\section{Выводы}

1. Содержание танинов в листьях растений увеличивается в течение всего периода активной вегетации и достигает максимального значения в августе.

2. На содержание танинов в листьях влияет степень техногенной нагрузки и особенности метеорологических условий вегетационного периода.

3. Динамика накопления танинов в листьях древесных растений имеет видовую специфику.

4. Конденсированные танины, на наш взгляд, являются активными участниками адаптационных процессов у древесных растений в условиях техногенного стресса. 5) Для создания примагистральных посадок предпочтение следует отдавать таким видам древесных растений, как клен остролистный, клен американский, береза повислая, а применение липы мелколистной и тополя бальзамического - ограничить. Для создания насаждений санитарно-защитных зон промышленных предприятий наиболее обоснованными древесными породами являются липа мелколистная, тополь бальзамический, клен остролистный и береза повислая.

\section{Список литературы}

1. Бухарина И.Л., Поварницина Т.М., Ведерников К.Е. Эколого-биологические особенности древесных растений в урбанизированной среде : монография. Ижевск, 2007. 216 с.

2. Бухарина И.Л., Кузьмин П.А., Шарифуллина А.М. Содержание низкомолекулярных органических соединений в листьях деревьев при техногенных нагрузках // Лесоведение. 2014. №2. С. 20-26.

3. Неверова О.А., Колмогорова Е.Ю. Древесные растения и урбанизированная среда : экологические биотехнологические аспекты. Новосибирск, 2003. 222 с.

4. Кулагин А.А., Шагиева Ю.А. Древесные растения и биологическая консервация промышленных загрязнителей / отв. ред. Г.С. Розенберг. М., 2005. 190 с.

5. Иванов Л.А. Морфологические и биохимические особенности растений бореальной зоны с разными типами адаптивных стратегий : автореф. дисс. ...канд. биол. наук. Томск, 2001. 25 с.

6. Чупахина Г.Н. Масленников П.В. Адаптация растений к нефтяному стрессу // Экология. 2004. №5. С. 330-335.

7. Трошкова И.Ю., Винокурова Р.И. Особенности накопления бетулина и суберина в коре деревьев Betula pendula, произрастающих на территориях различного функционального использования // Современные проблемы аграрной науки и пути их решения: матер. Всерос. науч.-практ. конф. Ижевск, 2005. С. $278-282$.

8. Whittehead D.C., Dibb H., Hartley R.D. Extractant $\mathrm{pH}$ and release of phenolic compounds from soils, plant roots and leaf litter // Soil Biol. Biochem. 1981. Vol. 13. Pp. 343-348.

9. Государственный доклад «О состоянии природных ресурсов и об охране окружающей среды Республики Татарстан в 2013 г.». Казань, 2014. 427 с.

10. Атлас Республики Татарстан / гл. ред. Г.В. Поздняк. М., 2005. 700 с.

11. ГОСТ 17.4.3.01.-83. Охрана природы. Почвы. Общие требования к отбору проб. М., 1983. 5 с.

12. Методические указания по оценке городских почв при разработке градостроительной и архитектурностроительной документации / Коллектив авторов. М., 1996. 36 с.

13. Бухарина И.Л., Любимова О.В. Биохимия растений : учеб.-метод. пособие. Ижевск, 2009. 50 с.

Поступило в редакичию 22 апреля 2015 г. 
Bukharina I.L. ${ }^{{ }^{*}}$, Kuz'mina A.M. ${ }^{2}, K^{\prime}$ ' $z^{\prime}$ min P.A. ${ }^{3}$ FEATURES OF THE CONTENT OF TANNINS IN LEAVES OF WOOD PLANTS IN THE TECHNOGENIC ENVIRONMENT

${ }^{I}$ Udmurt State University, Universitetskaia st., 1, Izhevsk, 426034 (Russia), e-mail: buharin@udmlink.ru

${ }^{2}$ Izhevsk State Agricultural Academy, Kirova st., 16, Izhevsk, 426033 (Russia)

${ }^{3}$ Kazan Federal University, Kazanskaia st., 89, Yelabuga, 423600 (Russia)

Dynamics of the content of tannins in leaves of wood species of the plants growing in plantings of various ecological categories is studied. Researches are conducted on the example of the city of Naberezhnye Chelny of the republic of Tatarstan. The complex index of pollution of the atmosphere of the city shows very high pollution and excess of level of maximum permissible concentration on benzopyrene, formaldehyde, phenols and carbon oxides and nitrogen. Participation of this metabolite in adaptive reactions of wood plants to conditions of the technogenic environment is shown. It is revealed that the content of tannins in leaves of plants increases during the entire period of active vegetation and reaches the maximum value in august. The content of tannins in leaves is influenced by degree of technogenic loading and feature of weather conditions of the vegetative period. Dynamics of accumulation of tannins in leaves of wood plants has specific specifics. For creation the trunk of landings the preference should be given to such species of wood plants as acer platanoides, acer negundo, betula pendula, tilia cordata and populus balsamifera - to limit application of a linden. For creation of plantings of sanitary protection zones of the industrial enterprises the most reasonable tree species are tilia cordata, populus balsamifera, acer platanoides and betula pendula.

Keywords: tannins, wood plantings, technogenic environment, adaptive reactions.

\section{References}

1. Bukharina I.L., Povarnitsina T.M., Vedernikov K.E. Ekologo-biologicheskie osobennosti drevesnykh rastenii v urbanizirovannoi srede: monografiia. [Ecological and biological characteristics of woody plants in the urban environment: a monograph]. Izhevsk, 2007, 216 p. (in Russ.).

2. Bukharina I.L., Kuz'min P.A., Sharifullina A.M. Lesovedenie, 2014, no. 2, pp. 20-26. (in Russ.).

3. Neverova O.A., Kolmogorova E.Iu. Drevesnye rasteniia $i$ urbanizirovannaia sred: ekologicheskie biotekhnologicheskie aspekty. [Woody plants and urban environment: environmental aspects of biotechnology]. Novosibirsk, 2003, 222 p. (in Russ.).

4. Kulagin A.A., Shagieva Iu.A. Drevesnye rasteniia i biologicheskaia konservatsiia promyshlennykh zagriaznitelei. [Woody plants and biological preservation of industrial pollutants]. Ed. G.S. Rozenberg. Moscow, 2005, 190 p. (in Russ.).

5. Ivanov L.A. Morfologicheskie i biokhimicheskie osobennosti rastenii boreal'noi zony s raznymi tipami adaptivnykh strategii : avtoref. diss. ...kand. biol. nauk. [Morphological and biological features of boreal plants with different types of adaptive strategies: the dissertation author's candidate of biological sciences]. Tomsk, 2001, 25 p. (in Russ.).

6. Chupakhina G.N. Maslennikov P.V. Ekologiia, 2004, no. 5, pp. 330-335. (in Russ.).

7. Troshkova I.Iu., Vinokurova R.I. Sovremennye problemy agrarnoi nauki i puti ikh resheniia: mater. Vseros. nauch.prakt. konf. [Modern problems of agricultural science and solutions: Materials of All-Russian scientific-practical conference]. Izhevsk, 2005. C. 278-282. (in Russ.).

8. Whittehead D.C., Dibb H., Hartley R.D. Soil Biol. Biochem., 1981, vol. 13, pp. 343-348.

9. Gosudarstvennyi doklad «O sostoianii prirodnykh resursov $i$ ob okhrane okruzhaiushchei sredy Respubliki Tatarstan $v 2013$ g.» [State report "On the state of natural resources and environmental protection of the Republic of Tatarstan in 2013."]. Kazan, 2014, 427 p. (in Russ.)

10. Atlas Respubliki Tatarstan. [Atlas of the Republic of Tatarstan]. Ed. G.V. Pozdniak. Moscow, 2005, 700 p. (in Russ.).

11. GOST 17.4.3.01.-83. Okhrana prirody. Pochvy. Obshchie trebovaniia k otboru prob. [State standards 17.4.3.01.-83. Protection of Nature. Soils. General requirements for sampling]. Moscow, 1983, 5 p. (in Russ.).

12. Metodicheskie ukazaniia po otsenke gorodskikh pochv pri razrabotke gradostroitel'noi $i$ arkhitekturno-stroitel'noi dokumentatsii. [Guidelines for the evaluation of urban soils in the development of urban planning, architectural and construction documents]. Moscow, 1996, 36 p. (in Russ.).

13. Bukharina I.L., Liubimova O.V. Biokhimiia rastenii: ucheb.-metod. posobie. [Phytochemistry: teaching method. allowance]. Izhevsk, 2009, 50 p. (in Russ.).

Received April 22, 2015

Revised December 21, 2015

\footnotetext{
* Corresponding author.
} 